\author{
Research Article
}

\title{
Inhibitory effects of cardamonin on compound action potentials in frog sciatic nerves and the possible involvement of opioidergic pathway
}

\author{
Yogesvari Sambasevam ${ }^{1}$, Wong Siong Jiun ${ }^{1}$, Farihah Hanani Ghazali ${ }^{1}$, Ammar Izzati Amir Ramadan ${ }^{1}$, \\ Ahmad Akira ${ }^{1}$, Mohd Roslan Sulaiman ${ }^{1}$, Mohd Khairi Hussain ${ }^{1}$, Enoch Kumar Perimal ${ }^{1 *}$ \\ Department of Biomedical Science, Faculty of Medicine and Health Sciences, Universiti Putra Malaysia, 43400 UPM Serdang, Selangor Darul Ehsan, \\ Malaysia.
}

https://doi.org/10.28916/lsmb.1.1.2017.3

Received 1 September 2017, Revisions received 17 September 2017, Accepted 17 September 2017, Available online 18 September 2017

\begin{abstract}
Introduction: Active compounds derived from plants are able to inhibit nerve conduction. Cardamonin, a naturally occurring chalcone, manifests anti-nociceptive, anti-inflammatory and anti-neuropathy properties. Consequently, cardamonin may potentially inhibit nerve action potential, whereby, it affects the nerve conduction. Compound action potential is the sum of the activity which is measured from a nerve trunk. Objective: The experiment was carried out to investigate the inhibitory effect of cardamonin on compound action potentials and its possible mechanism of action on frog sciatic nerve. Methodology: LabTutor software was used to record compound action potentials in frog sciatic nerve. Sciatic nerve was isolated from the frog and soaked in Ringer's solution. Stimulating electrodes were used to stimulate the nerve and recording electrodes were used to record compound action potentials. Compound action potential of the nerve were recorded before and after treatments [vehicle, cardamonin $(0.5,1 \& 2 \mathrm{mg} / \mathrm{ml}) \&$ morphine $(3 \mathrm{mg} / \mathrm{ml})]$. Participation of opioid system was investigated by pre-treating the nerve with naloxone and followed by cardamonin. All the data were recorded and analysed via LabTutor software. The data were analysed by using Two-way ANOVA followed by Bonferonni's post hoc test with significant value at $P<0.05$. Results: The outcomes showed that all the doses of cardamonin significantly reduced the peak amplitude of compound action potential in frog sciatic nerves. Besides, co-treatment of naloxone and cardamonin significantly $(P<0.001)$ reversed the effect of cardamonin on peak amplitude of compound action potential, suggesting the involvement of opioid receptors to inhibit nerve conduction. Conclusion: Cardamonin reduces the nerve signal conduction via activation of opioid receptors to modulate pain and contribute to the analgesic effects.
\end{abstract}

Keywords: Cardamonin, Sciatic nerve, Compound Action Potentials, Opioid receptor

1.0

\section{Introduction}

Cardamonin (2', 4'-dihydroxy-6'-methoxychalcone), an active compound found in various zingiberous plant species (Gonçalves, Valente, \& Rodrigues, 2014) such as Alpinia blepharocalyx (Dong, Chen, Xu, Kadota, \& Namba, 1998), Alpinia rafflesiana (Chow et al., 2012) and Boesenbergia pandurata (Trakoontivakorn et al., 2001). Extensive studies had reported that cardamonin exhibits several biological properties, importantly, anti-nociceptive (Mi Kyung Park et al., 2014; M. K. Park et al., 2014; Wang et al., 2016), anti-neuropathic pain (Sambasevam et al., 2017), anti-inflammatory (Ahmad et al., 2006; Israf, Khaizurin, Syahida, Lajis, \& Khozirah, 2007; Lee et al., 2006), antiHIV (Tewtrakul, Subhadhirasakul, Puripattanavong, \& Panphadung, 2003), antineoplastic (Trakoontivakorn et al., 2001), antioxidant (Bajgai, Prachyawarakorn, Mahidol, Ruchirawat, \& Kittakoop, 2011) and hypoglycemic (Yamamoto et al., 2011) activities. Besides, cardamonin had been reported to modulate receptors and ion channels. For instance, cardamonin isolated from A. katsumadai, act as a selective TRPA1 antagonist responsible for the anti-nociceptive effect (Wang et al., 2016), in which modulation of TRP channels will inhibit nerve excitability (Ohtsubo, Fujita, Matsushita, \& Kumamoto, 2015). Taken together, it is possible that analgesic effects produced by cardamonin are due to inhibition of synaptic transmission and action potential conduction in pain pathways.

Compound action potentials (CAPs) are seen in nerve trunks which contains hundreds of nerve fibres in parallel with various sizes of diameter and thresholds. The recorded potential from the nerve trunk is the sum of the excitability of nerve fibers (Marieb \& Hoehn, 2007). Moreover, action potential is a signal which travel along the nerve fibres resulting in electrical membrane potential to rapidly rise or fall (Lodish, 2008). Previous studies had revealed that plant-derived active compounds are able to reduce the peak amplitude of compound action potentials. For instance, peppermint component menthol (Kawasaki, Mizuta, Fujita, \& Kumamoto, 2013), wasabi component allyl isothiocyanate and cinnamon component cinnamaldehyde (Matsushita, Ohtsubo, Fujita, \& Kumamoto, 2013) as well as aroma-oil compounds (Ohtsubo et al., 2015) had been proven to have depressive action on CAPs. Thus, it is possible that cardamonin also may induce reduction of action potential in peripheral nerve.

\footnotetext{
* Correspondence: Department of Biomedical Science, Faculty of Medicine and Health Sciences, Universiti Putra Malaysia, 43400 UPM Serdang, Selangor Darul Ehsan, Malaysia.
}

e-Mail: enoch@upm.edu.my

(C) 2017 by the Author(s). Life Sciences, Medicine and Biomedicine (ISSN: 2600-7207) Published by Biome Journals. Wholly owned by Biome Scientia Sdn Bhd., previously by WWH Networks Sdn Bhd. Attribution-ShareAlike 4.0 International (CC BY-SA 4.0). This open access article is distributed based on the terms and conditions of the Creative Commons Attribution license https://creativecommons.org/licenses/by-sa/4.0/ 
On the other hand, descending opioidergic pathway plays role in modulating the pain signal transmitted from the nociceptors in peripheral nerve fibres. Activation of the localised opioid receptors indirectly inhibit the excitatory synaptic transmission triggering antinociceptive effects (Gissen, Gugino, Datta, Miller, \& Covino, 1987; Jaffe \& Rowe, 1996). Activation of opioid receptors (mu, delta , and kappa) will decrease the conductance of voltage-gated $\mathrm{Ca}^{2+}$ channels and opening of rectifying $\mathrm{K}^{+}$channels, directly inhibiting neuronal hyperexcitability, leads to analgesic effects (Stein, 2016). Based on the previous studies, action potential in nerve fibres was blocked by the treatment of opioid drugs. For instance, sufentanil and fentanyl suppress the peak amplitudes of CAPs measure from peripheral nerve fibres (Gissen et al., 1987) and inhibit action potential (Jaffe \& Rowe, 1996).

We previously had reported the involvement of opioid receptors in cardamonin-induced antihyperalgesic and antiallodynic properties (Sambasevam et al., 2017). Thus, we hypothesized that cardamonin may potentially inhibit compound action potential via modulation of opioid receptors localised in peripheral nerve fibres. To our knowledge, there are no data has been reported on the effects of cardamonin on nerve conduction in inhibiting pain circuit. To address this issue, the present study speculates how cardamonin used to relieve pain affect CAPs measured from the frog sciatic nerve.

\section{Materials \& Methods}

2.1 Animals

Bullfrogs (Rana catesbeiana) weighing 200-300g, housed in the aquarium and fed with living insects and water ad libitum. This study was approved by the Institutional Animal Care and Use Committee (IACUC), UPM (AUP No.: U001/2017). All efforts were made to minimize the number of animal used and animal suffering.

The method used to isolate frog sciatic nerve has been described previously (Kosugi, Mizuta, Fujita, Nakashima, \& Kumamoto, 2010; Matsushita et al., 2013; Ohtsubo et al., 2015). Frogs were pithed and the sciatic nerve was dissected from the lumbar plexus to the knee in Ringer solution. The sciatic nerve was soaked in the petri dish which contained Ringer solution and then placed in the nerve chamber for CAPs measurement. The Ringer solution was prepared by using $(\mathrm{mM})$ : $\mathrm{NaCl}, 115.5 ; \mathrm{KCl}, 2.0 ; \mathrm{CaCl}_{2}, 1.8 ; \mathrm{Na}_{2} \mathrm{HPO}_{4}, 1.3 ;(\mathrm{pH}=7.0)$.

\section{3}

\section{Materials}

Cardamonin with the purity of $\geq 98 \%$ was prepared by dissolving in Tween20 and normal saline at a ratio of 5:95 (v/v). Drugs such as morphine sulphate and naloxone hydrochloride were dissolved in normal saline. All compound and drugs were purchased from SigmaAldrich (St. Louis, MO, USA).

Table 1: Experiment I - CAPs inhibition by cardamonin

\begin{tabular}{ll}
\hline Experimental groups & Treatment \\
\hline $\mathbf{1}$ & Vehicle $(95 \%$ normal saline \& 5\% Tween 20$)$ \\
$\mathbf{2}$ & Cardamonin $(0.5 \mathrm{mg} / \mathrm{ml})$ \\
$\mathbf{3}$ & Cardamonin $(1 \mathrm{mg} / \mathrm{ml})$ \\
$\mathbf{4}$ & Cardamonin $(2 \mathrm{mg} / \mathrm{ml})$ \\
$\mathbf{5}$ & Morphine $(3 \mathrm{mg} / \mathrm{ml})$ \\
\hline
\end{tabular}

Table 2: Experiment II - Involvement of opioid pathway

\begin{tabular}{ll}
\hline Experimental groups & Treatment \\
\hline $\mathbf{1}$ & \\
$\mathbf{2}$ & Vehicle $(95 \%$ normal saline \& $5 \%$ Tween 20$)$ \\
$\mathbf{3}$ & Cardamonin $(1 \mathrm{mg} / \mathrm{ml})$ \\
$\mathbf{4}$ & Naloxone hydrochloride $(0.1 \mathrm{mg} / \mathrm{ml})$ \\
\hline
\end{tabular}

LabTutor software (ADInstruments Pty Ltd., Australia) consists of a data capture module known as Powerlab connected to a computer, was used throughout the experiment. As shown in the LabTutor software, the sciatic nerve was placed on the nerve bath chamber where it was connected with two stimulating electrodes and two sets of recording electrodes. Stimulating electrodes were used to stimulate the sciatic nerve, while the recording electrodes were used to record CAPs. The stimulation was started at $10 \mathrm{mV}$, where CAPs curve having $0.5 \mathrm{~ms}$ duration and varying strength were used. The stimulation, $200 \mathrm{mV}$ had been chosen to generate the CAPs. CAPs were recorded before and after the treatments (Table 1 \& Figure 1). The procedure was quickly performed to avoid the sciatic nerve from losing moisture. The data were recorded in the LabTutor software. A stimulus artifact was produced followed by a CAP when the nerve was stimulated. The difference between baseline and CAP highest peak value was recorded as the peak amplitude of the CAP (Matsushita et al., 2013; Ohtsubo et al., 2015). 
The peak amplitude of the CAP was dependent on the strength of stimulus given to the sciatic nerve. As the stimulus strength was increased, the CAP peak amplitude was enhanced and attained a maximal value. As done previously (Matsushita et al., 2013; Ohtsubo et al., 2015), the peak amplitude of the maximal CAP was analyzed. All the experiments were conducted at room temperature $\left(22-27^{\circ} \mathrm{C}\right)$.

\subsection{Involvement of Opioid Receptor}

The involvement of opioid receptor was investigated based on (Mizuta, Fujita, Nakatsuka, \& Kumamoto, 2008) with minor modification. Each experimental group (Table 2) consists of six frog sciatic nerves. The CAPs of the sciatic nerves were recorded for each treatment procedure (Figure 2). Then, the nerve was soaked in the respective treatment according to the experimental groups. Throughout the experiment, the CAPs were measured and recorded using LabTutor software.

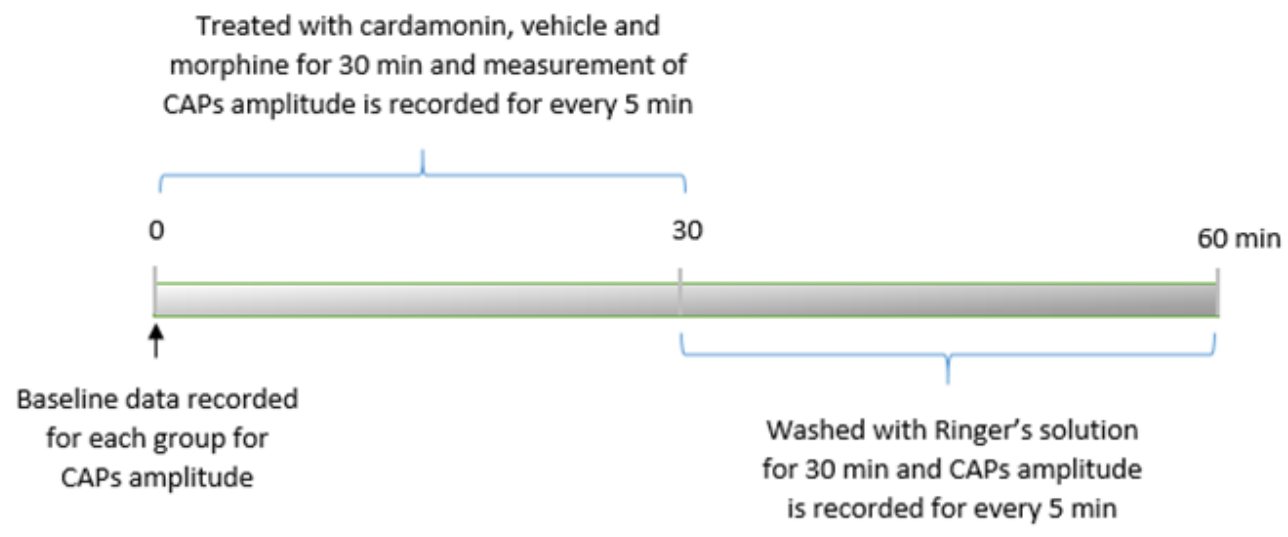

Figure 1: Protocol for the CAP inhibitory effects of cardamonin

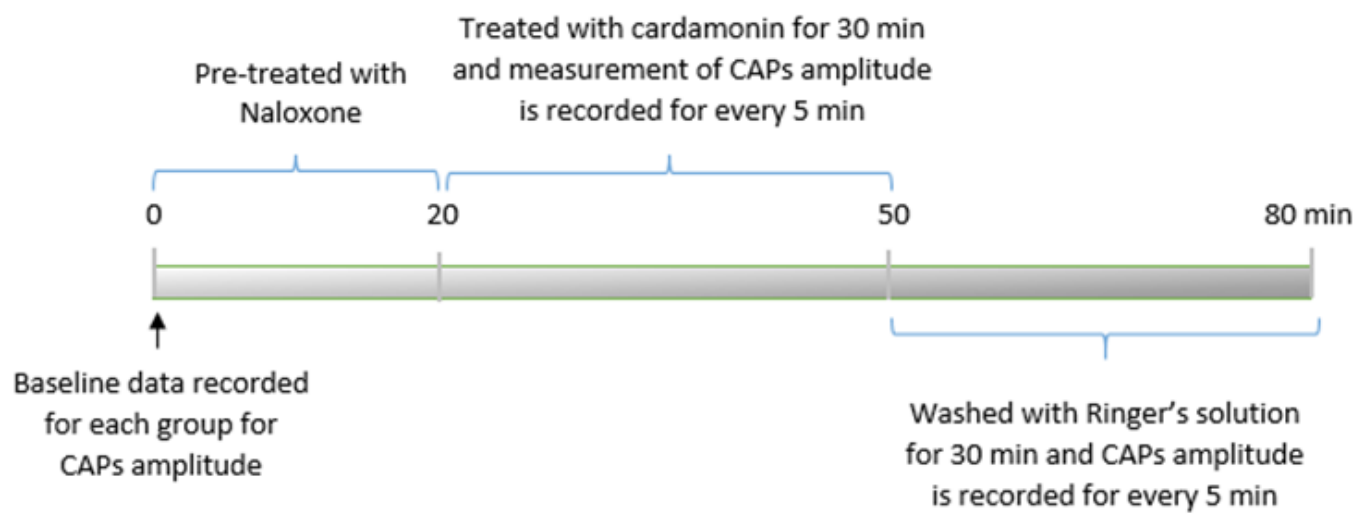

Figure 2: Protocol for the involvement of opioid receptors

Data were indicated as mean \pm SEM and statistically analysed by using GraphPad Prism v5.0 software (GraphPad San Diego, CA). Statically differences between groups were determined by One-Way Analysis of Variance (ANOVA) followed by Bonferonni's post hoc test. The results were considered significant at $P<0.05$. In all cases, $n$ refers to the number of sciatic nerves studied.

\subsection{Results}

3.1 Effects of cardamonin on frog sciatic nerve CAPs

Effects of cardamonin on CAPs were examined in total of 54 sciatic nerves, and when measured the nerves' CAP, an average value of $23.31 \mathrm{mV}$ was obtained, a value similar with those reported previously (Kosugi et al., 2010; Mizuta et al., 2008).

First, the effect of cardamonin on CAPs obtained from the frog sciatic nerve was investigated. Sciatic nerve soaked into $1 \mathrm{mg} / \mathrm{ml}$ of cardamonin for 30 mins suppress the peak amplitude of the CAP as shown in Figure 3A (upper panel). Figure 3A (lower panel) shows the average time course of the change in peak amplitude after soaking in the cardamonin $(1 \mathrm{mg} / \mathrm{ml})$, relative to control obtained from six sciatic nerves. Cardamonin-induced reduction in CAP amplitude at 30 mins following exposure, the peak amplitude of the CAP was reduced to 53.02 
$\pm 6.1 \%(P<0.001)$ of control. The treated nerve was then returned to drug-free Ringer's solution (washout) for 30 mins, and the CAP peak amplitude recovered to $90.44 \pm 7.8 \%(P<0.05)$ of the control.

Figure 3B shows the time course of changes in CAP peak amplitude with an increase in time after soaking the sciatic nerve into vehicle, cardamonin at different concentrations $(0.5,1 \mathrm{and} 2 \mathrm{mg} / \mathrm{ml})$ and morphine $(3 \mathrm{mg} / \mathrm{ml})$. Based on the graph, at $30 \mathrm{mins}, 0.5 \mathrm{mg} / \mathrm{ml}(65.95$ $\pm 2.1 \%, P<0.01), 1 \mathrm{mg} / \mathrm{ml}(53.0 \pm 6.1 \%, P<0.001)$ and $2 \mathrm{mg} / \mathrm{ml}(59.9 \pm 1.9 \%, P<0.001)$ of cardamonin showed significant reduction of CAP peak amplitude when compared to control group $(84.87 \pm 4.5 \%)$. However, $1 \mathrm{mg} / \mathrm{ml}$ of cardamonin produced a pronounced inhibition of CAP at 20 mins of soaking and sustained for 10 mins. Positive control, morphine (3mg/ml) shows significant reduction of CAP peak amplitude $(55.43 \pm 4 \%)$ when compared to control group.

$3 \mathrm{~A}$
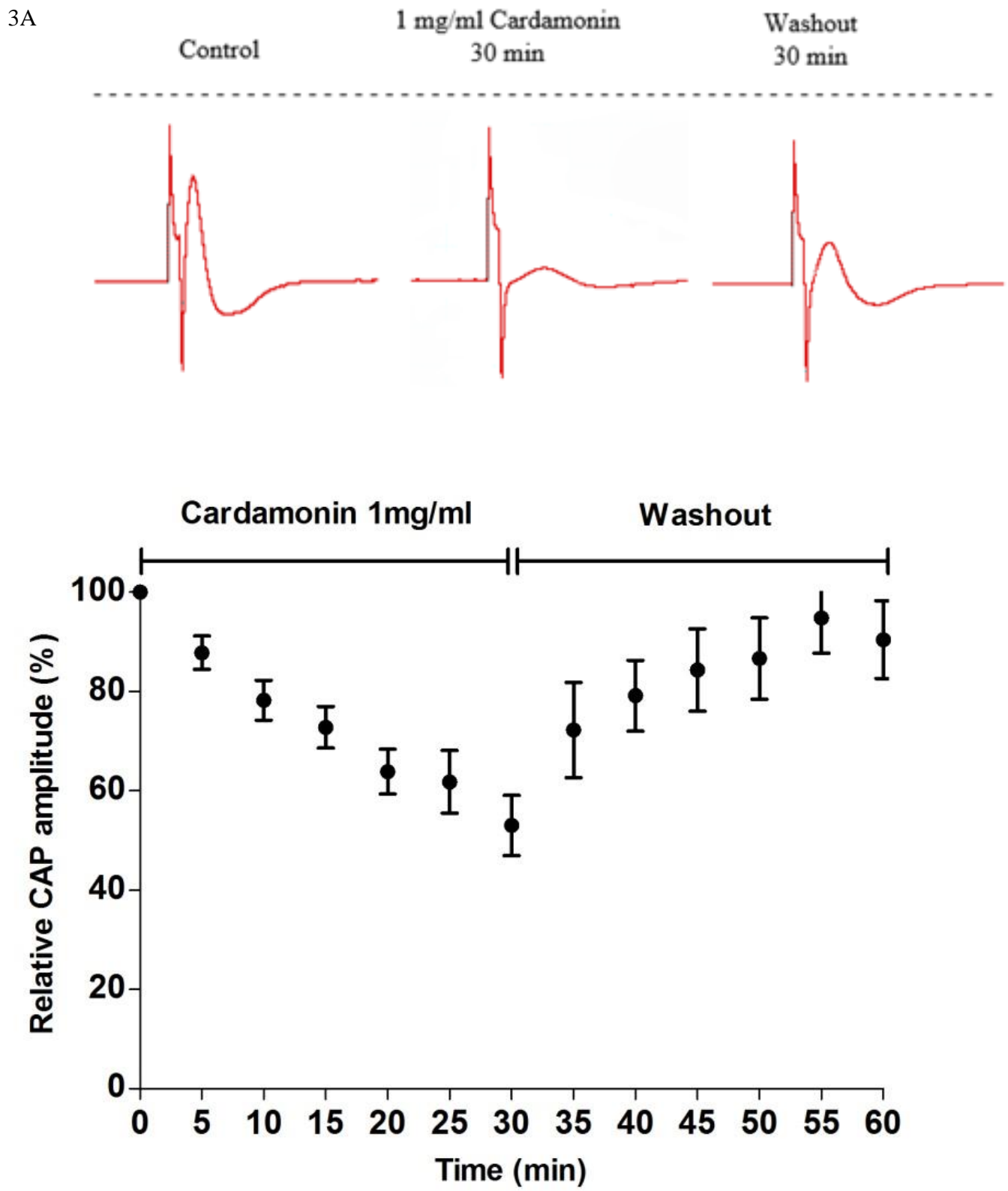

Figure 3A: Upper Panel - Recording of CAPs before treatment at $0 \mathrm{~min}, 30 \mathrm{~min}$ after exposure to cardamonin $(1 \mathrm{mg} / \mathrm{mL})$ at $30 \mathrm{~min}$ after washout. Lower Panel - Average time course of changes in CAP peak amplitudes following exposure to cardamonin $(1 \mathrm{mg} / \mathrm{mL})$ for $30 \mathrm{~min}$, relative to baseline. Results are shown as mean \pm S.E.M., $n=6$ nerves per group. 


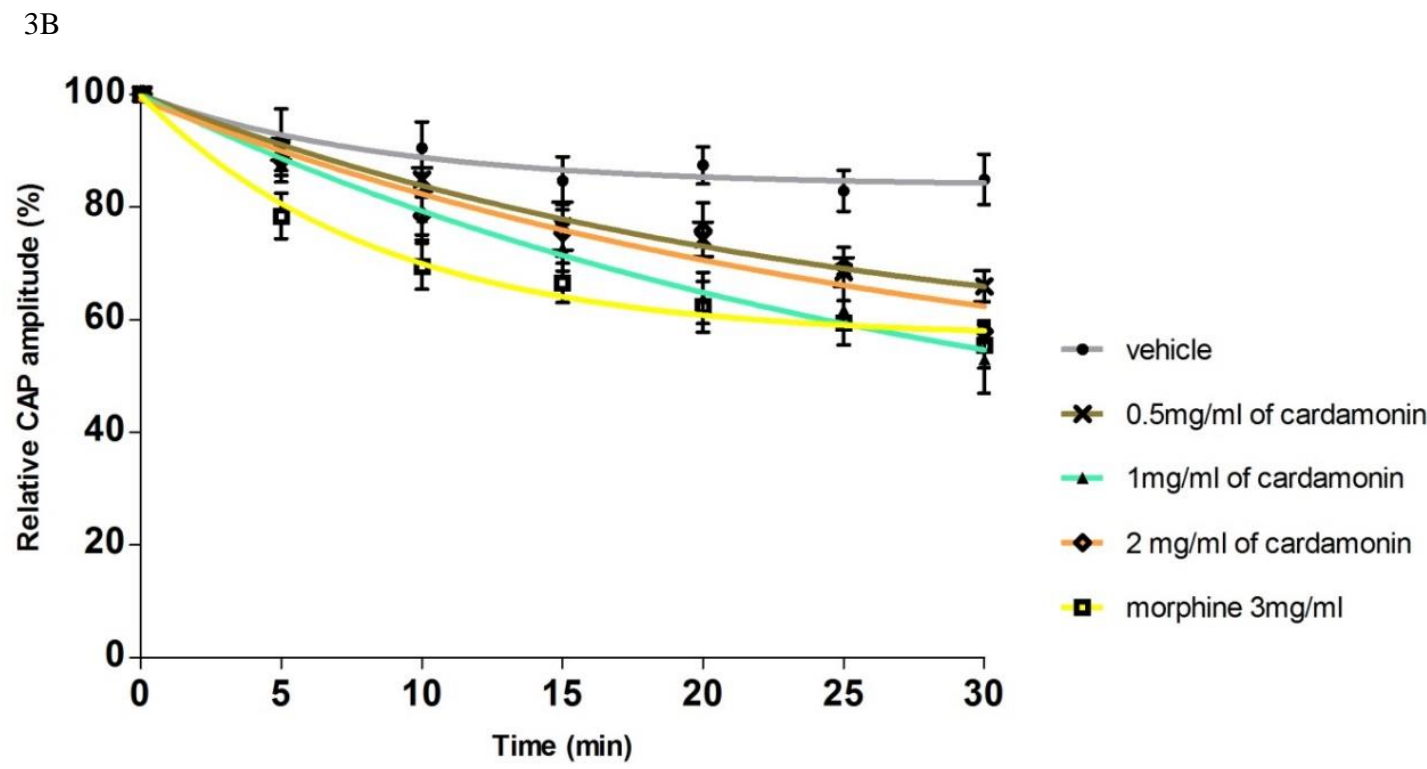

Figure 3B: Comparison in average time course among CAP peak amplitude changes produced by vehicle, cardamonin $(05,1$ and $2 \mathrm{mg} / \mathrm{mL})$ and morphine $(3 \mathrm{mg} / \mathrm{mL})$.

In order to investigate the involvement of opioid pathway in cardamonin-induced reduction of CAP peak amplitude, the sciatic nerves were soaked in a non-specific opioid-receptor blocker, naloxone hydrochloride $(0.1 \mathrm{mg} / \mathrm{ml})$ for $20 \mathrm{mins}$ prior to cardamonin $(1 \mathrm{mg} / \mathrm{ml})$. Figure 4 illustrates the significant reversal $(93.22 \pm 6.2 \%, P<0.001)$ of reduced CAP peak amplitude produced by cardamonin.

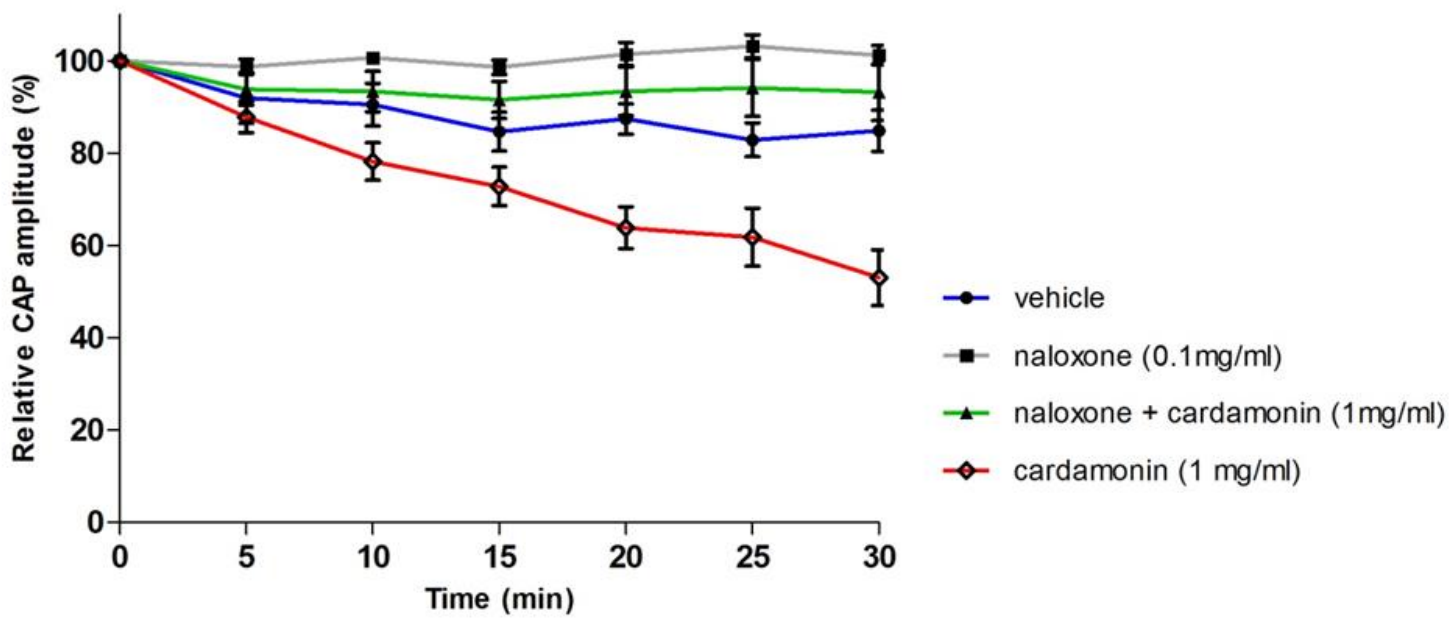

Figure 4: Effect of pre-treatment of naloxone $(0.1 \mathrm{mg} / \mathrm{mL})$ with cardamonin on the CAPs amplitude of frog sciatic nerve.

\section{Discussion}

The present study demonstrated that cardamonin depresses the CAP peak amplitude measured from frog sciatic nerve. Based on the graphs, cardamonin reduced the peak amplitude of CAP in a concentration-independent manner. Cardamonin reversibly inhibited CAPs peak amplitude, where the peak amplitude was observed to be recovered after washout as shown in Figure 3A. All the doses of cardamonin in the present study demonstrated inhibition of compound action potential. However, $1 \mathrm{mg} / \mathrm{ml}$ of cardamonin seemed to be the most effective in inhibiting the CAPs when compared to the control group. Morphine, positive control used in this study significantly reduced the CAP when compare with control group. This outcome is further supported by one the studies coined that morphine inhibits the CAP peak amplitude via involvement of opioidergic pathway (Jurna \& Grossmann, 1977).

Compound action potential, the basic element of nerve activity, is important to regulate physiological and pathological processes (Li et al., 2010). Among the peripheral nerve fibres, sciatic nerve is found to be the largest nerve and frequently used to investigate processes associated with peripheral nervous system (Pandey \& Deshpande, 2012). The changes in neuronal excitability observed in the present study suggested that cardamonin possibly act as a local anesthetic agent. This in agreement with previous study showing that cardamonin possessed anti-nociceptive (Mi Kyung Park et al., 2014) and anti-neuropathic pain activities (Sambasevam et al., 2017). Cardamonin also been reported 
that it had antagonistic effect on the TRPA1 receptors and thus block the nerve signal transmission (Caterina et al., 1997; Wang et al., 2016). Consistent with this idea, the nerve conduction possibly inhibited by modulation of TRP receptors as seen in previous studies carried out by using cinnamaldehyde and allyl isothiocyanate on frog sciatic nerve (Matsushita et al., 2013).

Cardamonin, for the first time, revealed its ability in inhibiting the CAPs. Thus, it is possible to investigate the underlying mechanisms. We examined the involvement of opioid pathway by using a non-specific opioid receptor antagonist, naloxone hydrochloride. Based on the findings, cardamonin-induced CAP peak reduction was significantly reversed, indicating the input of opioid receptors in modulating the nerve action potential. We previously reported that cardamonin alleviates pain response observed in chronic constriction injuryinduced neuropathic pain in in vivo via involvement of opioid receptors localised in nervous system (Sambasevam et al., 2017). Combining with our previous findings, our current results further insights into the depressive action of cardamonin in action potential as an important mechanism in producing analgesic effects in pathological condition.

Opioids are carried from brain to periphery by P-glycoprotein, thus it is possible that centrally-administered opioids act on both central and peripheral nervous system (King, Su, Chang, Zuckerman, \& Pasternak, 2001). On the other hand, drugs that does not able to penetrate blood brain barrier, such as $\mathrm{N}$-methyl-morphine demonstrated antinociception in an acetic acid writhing model in mice, suggesting the crucial role of opioids in the peripheral nervous system (Shannon \& Lutz, 2002). Taken together, the role of opioids in the periphery seems to be mediated by opioid receptors in the peripheral terminals of afferent fibres (Labuz, Mousa, Schäfer, Stein, \& Machelska, 2007). The present study suggests the possible role of cardamonin act as an agonist on the receptors expressed on the peripheral nerve fibres, depresses the action potential, thereby exhibiting analgesic effects (Sambasevam et al., 2017). Besides, cardamonin is classified under flavonoids. Flavonoids exhibits analgesic effects by activating the opioidergic system (Higgs, Wasowski, Loscalzo, \& Marder, 2013). This further supports the findings that cardamonin inhibited nerve conduction in the peripheral nerve such as sciatic nerve by activating the localised opioid receptors.

\section{Conclusion}

In conclusion, cardamonin possibly inhibits nerve conduction in a manner independent on their concentrations. The cardamonininduced inhibition is antagonized by naloxone, suggesting that cardamonin-induced CAP amplitude reduction was due to the activation of opioid receptor.

6.0

\section{Declaration}

The authors declare no conflicts of interest in this work.

\section{Acknowledgements}

The authors thank the Faculty of Medicine and Health Sciences, University Putra Malaysia, and the Physiology Laboratories for providing the necessary support for the study. This research was supported by the Universiti Putra Malaysia Grant (GP-IPM/2014/9433700).

Ahmad, S., Israf, D. A., Lajis, N. H., Shaari, K., Mohamed, H., Wahab, A. A., Somchit, M. N. (2006). Cardamonin, inhibits pro-inflammatory mediators in activated RAW 264.7 cells and whole blood. Eur J Pharmacol, 538(1-3), 188-194. doi:10.1016/j.ejphar.2006.03.070

Bajgai, S. P., Prachyawarakorn, V., Mahidol, C., Ruchirawat, S., \& Kittakoop, P. (2011). Hybrid flavan-chalcones, aromatase and lipoxygenase inhibitors, from Desmos cochinchinensis. Phytochemistry, 72(16), 2062-2067.

Caterina, M. J., Schumacher, M. A., Tominaga, M., Rosen, T. A., Levine, J. D., \& Julius, D. (1997). The capsaicin receptor: a heat-activated ion channel in the pain pathway. Nature, 389(6653), 816-824.

Chow, Y.-L., Lee, K.-H., Vidyadaran, S., Lajis, N. H., Akhtar, M. N., Israf, D. A., \& Syahida, A. (2012). Cardamonin from Alpinia rafflesiana inhibits inflammatory responses in IFN- $\gamma /$ LPS-stimulated BV2 microglia via NF- $\mathrm{kB}$ signalling pathway. Int Immunopharmacol, 12(4), 657-665.

Dong, H., Chen, S.-X., Xu, H.-X., Kadota, S., \& Namba, T. (1998). A new antiplatelet diarylheptanoid from Alpinia blepharocalyx. J Nat Prod, 61(1), 142-144.

Gissen, A. J., Gugino, L. D., Datta, S., Miller, J., \& Covino, B. G. (1987). Effects of fentanyl and sufentanil on peripheral mammalian nerves. Anesth Analg, 66(12), 1272-1276.

Gonçalves, L. M., Valente, I. M., \& Rodrigues, J. A. (2014). An overview on cardamonin. J Med Food, 17(6), 633-640.

Higgs, J., Wasowski, C., Loscalzo, L. M., \& Marder, M. (2013). In vitro binding affinities of a series of flavonoids for $\mu$-opioid receptors. Antinociceptive effect of the synthetic flavonoid 3, 3-dibromoflavanone in mice. Neuropharmacology, 72, 9-19.

Israf, D. A., Khaizurin, T. A., Syahida, A., Lajis, N. H., \& Khozirah, S. (2007). Cardamonin inhibits COX and iNOS expression via inhibition of p65NF-kappaB nuclear translocation and Ikappa-B phosphorylation in RAW 264.7 macrophage cells. Mol Immunol, 44(5), 673679. doi:10.1016/j.molimm.2006.04.025

Jaffe, R. A., \& Rowe, M. A. (1996). A comparison of the local anesthetic effects of meperidine, fentanyl, and sufentanil on dorsal root axons. Anesth Analg, 83(4), 776-781.

Jurna, I., \& Grossmann, W. (1977). The effect of morphine on mammalian nerve fibres. Eur J Pharmacol, 44(4), 339-348.

Kawasaki, H., Mizuta, K., Fujita, T., \& Kumamoto, E. (2013). Inhibition by menthol and its related chemicals of compound action potentials in frog sciatic nerves. LIFE SCI, 92(6), 359-367.

King, M., Su, W., Chang, A., Zuckerman, A., \& Pasternak, G. W. (2001). Transport of opioids from the brain to the periphery by P-glycoprotein: peripheral actions of central drugs. Nat Neurosci, 4(3), 268-274.

Kosugi, T., Mizuta, K., Fujita, T., Nakashima, M., \& Kumamoto, E. (2010). High concentrations of dexmedetomidine inhibit compound action potentials in frog sciatic nerves without $\alpha 2$ adrenoceptor activation. Br J Pharmacol, 160(7), 1662-1676.

Labuz, D., Mousa, S. A., Schäfer, M., Stein, C., \& Machelska, H. (2007). Relative contribution of peripheral versus central opioid receptors to antinociception. Brain Res, 1160, 30-38. 
Lee, J.-H., Jung, H. S., Giang, P. M., Jin, X., Lee, S., Son, P. T., . . Lee, J. J. (2006). Blockade of nuclear factor-kB signaling pathway and anti-inflammatory activity of cardamomin, a chalcone analog from Alpinia conchigera. J Pharmacol Exp Ther, 316(1), 271-278.

Li, Z., Yang, J., Liu, J., Gong, C.-Y., Gan, J., Zhang, X., . . Li, G.-h. (2010). Reversible conduction block in isolated toad sciatic nerve by emulsified isoflurane. Anesth Analg, 110(4), 1024-1029.

Lodish, H. (2008). Molecular cell biology: Macmillan.

Marieb, E. N., \& Hoehn, K. (2007). Human anatomy \& physiology: Pearson Education.

Matsushita, A., Ohtsubo, S., Fujita, T., \& Kumamoto, E. (2013). Inhibition by TRPA1 agonists of compound action potentials in the frog sciatic nerve. Biochem Biophys Res Commun, 434(1), 179-184.

Mizuta, K., Fujita, T., Nakatsuka, T., \& Kumamoto, E. (2008). Inhibitory effects of opioids on compound action potentials in frog sciatic nerves and their chemical structures. LIFE SCI, 83(5), 198-207.

Ohtsubo, S., Fujita, T., Matsushita, A., \& Kumamoto, E. (2015). Inhibition of the compound action potentials of frog sciatic nerves by aroma oil compounds having various chemical structures. Pharmacol Res Perspect, 3(2).

Pandey, A. K., \& Deshpande, S. B. (2012). Bisphenol A depresses compound action potential of frog sciatic nerve in vitro involving Ca 2+dependent mechanisms. Neurosci Lett, 517(2), 128-132.

Park, M. K., Lee, H. J., Choi, J. K., Kim, H. J., Kang, J. H., Lee, E. J., . . Cho, H. Y. (2014). Novel anti-nociceptive effects of cardamonin via blocking expression of cyclooxygenase-2 and transglutaminase-2. Pharmacology Biochemistry and Behavior, 118, 10-15.

Park, M. K., Lee, H. J., Choi, J. K., Kim, H. J., Kang, J. H., Lee, E. J., . . Lee, C. H. (2014). Novel anti-nociceptive effects of cardamonin via blocking expression of cyclooxygenase-2 and transglutaminase-2. Pharmacol Biochem Behav, 118, 10-15. doi:10.1016/j.pbb.2013.12.019

Sambasevam, Y., Farouk, A. A. O., Mohamad, T. A. S. T., Sulaiman, M. R., Bharatham, B. H., \& Perimal, E. K. (2017). Cardamonin attenuates hyperalgesia and allodynia in a mouse model of chronic constriction injury-induced neuropathic pain: Possible involvement of the opioid system. Eur J Pharmacol, 796, 32-38.

Shannon, H. E., \& Lutz, E. A. (2002). Comparison of the peripheral and central effects of the opioid agonists loperamide and morphine in the formalin test in rats. Neuropharmacology, 42(2), 253-261.

Stein, C. (2016). Opioid receptors. Annu Rev Med, 67, 433-451.

Tewtrakul, S., Subhadhirasakul, S., Puripattanavong, J., \& Panphadung, T. (2003). HIV-1 protease inhibitory substances from the rhizomes of Boesenbergia pandurata Holtt. Songklanakarin J Sci Technol, 25(6).

Trakoontivakorn, G., Nakahara, K., Shinmoto, H., Takenaka, M., Onishi-Kameyama, M., Ono, H., .. . Tsushida, T. (2001). Structural analysis of a novel antimutagenic compound, 4-hydroxypanduratin A, and the antimutagenic activity of flavonoids in a Thai spice, fingerroot (Boesenbergia pandurata Schult.) against mutagenic heterocyclic amines. J Agric Food Chem, 49(6), 3046-3050.

Wang, S., Zhai, C., Zhang, Y., Yu, Y., Zhang, Y., Ma, L., . . Q Qiao, Y. (2016). Cardamonin, a Novel Antagonist of hTRPA1 Cation Channel, Reveals Therapeutic Mechanism of Pathological Pain. Molecules, 21(9), 1145.

Yamamoto, N., Kawabata, K., Sawada, K., Ueda, M., Fukuda, I., Kawasaki, K., . . Ashida, H. (2011). Cardamonin stimulates glucose uptake through translocation of glucose transporter-4 in L6 myotubes. Phytother Res, 25(8), 1218-1224. 